\title{
TikTok's Business Model Innovation and Development - Porter's Five Forces Model, Business Model Canvas and SWOT Analysis as Tools
}

\author{
Yuan Peng ${ }^{1, *}$ \\ ${ }^{1}$ School of Business Administration, Chongqing Technology and Business University, Chongqing 400020, China \\ *Corresponding author. Email: 971096617@qq.com
}

\begin{abstract}
With the development of Internet technology, information is spreading rapidly. Short videos have become a new medium for people to receive information, and TikTok occupies an essential position in the short video apps. This paper uses Porter's Five Forces Model to analyze TikTok's market competition before it was founded. The Business Canvas model explores the business model and various elements of TikTok at diverse stages. Finally, the SWOT model is used to analyze the current situation of TikTok in strengths, weaknesses, opportunities and threats, and find the future direction of TikTok's business model. The analysis shows that startups need to identify opportunities and refine their business models to grow continually. TikTok should adopt a turnaround and diversification strategy to seek growth. This study provides TikTok with advice for better iteration and other parallel platforms with lessons for innovation.
\end{abstract}

Keywords: TikTok, Business Canvas Model, Porter's Five Forces, SWOT analysis.

\section{INTRODUCTION}

With the advent of the Internet era, people's living standards are getting higher and higher, so are their requirements for entertainment methods. Short videos are one of the leading entertainment methods that have reaped a vast market. According to the 47th China Internet Development Statistics Report released by CNNIC, as of December 2020, the number of Internet users in China reached 989 million, mobile phone users 986 million, the Internet penetration rate $70.4 \%$, and short video users 873 million. As of November 2020, the number of users has reached 490 million, and daily activity has exceeded 600 million [1]. TikTok has become representative phenomenon of its time in less than five years, and its success helps explore. At present, there are few research on the dynamic changes in the business model of the short video TikTok app, so this paper attempts to explore how TikTok identifies market opportunities at the early stage and how seizes opportunities to develop its business model at each stage. It also summarises its resource advantages and explores its future development direction through the SWOT model.

\section{LITERATURE REVIEW}

\subsection{Porter's Five Forces Model}

In the 1980s, Michael Porter established the Five Forces model for industry analysis and business strategy. The Five Forces refer to the Threat of new entrants, competitive rivalry, Bargaining power of suppliers, The Threat of substitutes and Bargaining power of buyers. This paper will use Porter's Five Forces model, combined with the characteristics of a mobile short video, to analyze the competition and cooperative interaction between market forces and industry players when TikTok is of its start-up.

\subsection{Business Model Analysis}

Different scholars have different definitions of business models. Amit and Zott [2] consider the business model as a system of transactions designed to identify opportunities and create value in a changing market environment, consisting of three main elements: transaction content, transaction structure, and transaction governance. Richardon's [3] value theory highly summarises a business model's 
components as the value proposition, the value creation and delivery system and value capture. This paper uses a business model derived from Alex Osterwalder and Yves Pigneur's Business Canvas Model [4], a generic tool for describing, visualising, evaluating and innovating business models. An exact business model can cope with the uncertainties faced by start-ups. The design of a business model is not only relevant to the creation of a company, but also crucial to gaining a competitive advantage and further growth. Against the backdrop of increased competition and changing market demand, TikTok will face various pressures, and it will turn external pressure into internal innovation. Therefore, this paper uses the Business Model Canvas tool to analyze how TikTok has adapted its business model at various stages to facilitate its growth.

\subsection{SWOT Analysis}

The SWOT analysis was introduced in 1971 by Harvard professor Kennet Andrews in his "Concept of Corporate Strategy". Heinz Weihrich of the University of San Francisco later improved this analysis by introducing the SWOT matrix. $\mathrm{S}$ is Strengths, W is Weaknesses, O is Opportunities, and $\mathrm{T}$ is Threats. This paper combines TikTok's external environment, industry environment and internal environment with its development strategy through

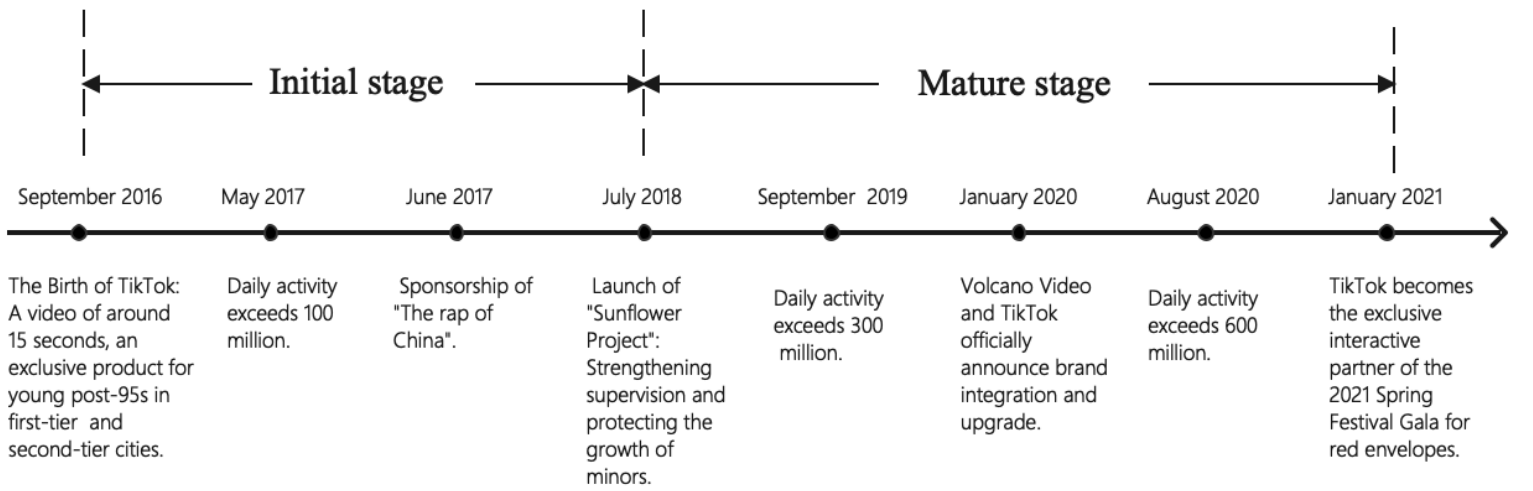

Figure 1 The History of TikTok.

\subsection{Development of Short Videos in 2016}

In 2016, TikTok was in the early stages to entry into the short video industry. The development of the mobile Internet in China has gradually matured, with $3 \mathrm{G} / 4 \mathrm{G}$ users growing. According to the research, in 2016, the total number of $4 \mathrm{G}$ mobile phone users has reached 390 million [6]. Mobile social networking and mobile video have become a meaningful way to fill people's fragmentation, laying the foundation for short videos' popularity. Short videos have become
SWOT analysis and makes suggestions for its future development.

\section{CASE STUDY}

\subsection{The History of TikTok}

TikTok is a short music video app targeted at young people, with the concept of "recording the good life", and is dedicated to creating a short music video community. To study the longitudinal dynamics of TikTok, this paper divides its entrepreneurial process. Drawing on Zhang Xiao and Li Jia's research [5], the entrepreneurial stages of TikTok can be divided into the initial stage (2016.92018.5) and the mature development stage (2018.62021.3).In the initial start-up stage, TikTok focused heavily on upgrading and improving its features, constantly introducing optimised features; In addition, it sponsored programmes such as "The rap of China" to expand its market share. In the maturity stage, TikTok strengthened its regulation and catered to policies by launching an anti-addiction system and the "Sunflower Project". TikTok was officially launched in September 2016, and its daily activity exceeded 100 million in 2017, 300 million in 2019, and 600 million by 2020. Behind the significant growth of TikTok's daily activity, its business model is worth exploring. 


\subsection{Porter's Five Forces Model of TikTok in 2016}

\subsubsection{Threat of New Entrants}

A company considering entering an industry needs to evaluate the overall development prospects and profitability levels. According to iiMedia Research[6], as of July 1, 2016, the short video industry has received a total of 43 investments, including the completion of Series D financing by One Technology and the completion of Series C financing by MeiTu and musical.ly. The number of investments and financing in the short video industry continues to grow, with bright development prospects and a high attraction for entrants. Potential entrants to TikTok are mainly internet giants, such as Alibaba and Baidu. Alibaba can increase the video portal in Taobao, a popular shopping app of it, to attract web traffic for its short video app. Baidu has advanced algorithms to analyze users' historical behaviours to hold on to users' interests.

\subsubsection{Competitive Rivalry}

In 2016, short video platforms are mainly divided into two categories: tool-based apps and integrated/social app. Tool-based apps include Xiaoying, Xiaogaxiu and MeiPai, which are convenient to help ordinary users produce and share content. The social platform type apps are Second Beat and Racer, the users of which are both viewers and creators of content. The following analysis is made of the representatives of the two types:

Kwai: Kwai focuses on creating a platform for ordinary people to record their lives, with user groups mainly concentrated in third-tier and fourth-tier cities and generally not highly educated.

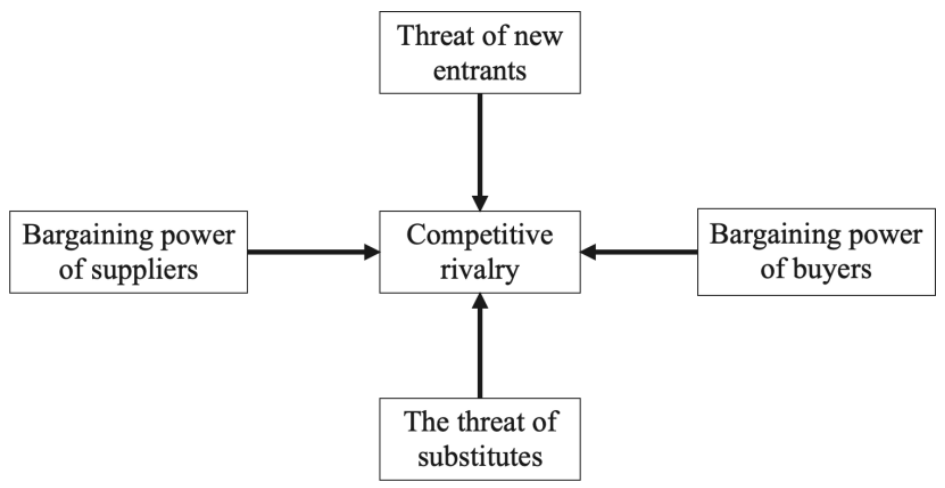

Figure 2 Porter's Five Forces Model.

MeiPai: MeiPai has an advantage in beautifying pictures and captures the characteristics of users. The market is in a position to pursue beautiful and sophisticated video effects. Users are mostly senior white-collar workers or school students with a high level of education.

\subsubsection{Bargaining Power of Suppliers}

Quality content is the foundation for short-form videos platforms to attract users, and the suppliers of short-form video are the originators of the videos. The relationship between the medium (TikTok) and the content suppliers (video originators) is one of interdependence in terms of the business model and mutual play in terms of interests. For TikTok, if it wants to stand out in short videos, quality content is the core competitiveness. As a result, TikTok prefers to be managed centrally. Video originators believe that the more channels there are for content distribution, the more opportunities they will gain exposure. For them, the risk of being on only one platform is too significant. They prefer to make videos on multiple platforms simultaneously. In 2016, on the one hand, the platform (TikTok) continued to build commercial platforms to increase its voice. On the other hand, TikTok developed its content through subsidies, with the platform side temporarily dominating the position. As a result, the bargaining power of content suppliers was low.

\subsubsection{The Threat of Substitutes}

For TikTok, the main alternative threats are traditional media, mobile online long-form video and social networking platforms.

\subsubsection{Traditional Media: TV, Newspapers and $\underline{\text { Radio }}$}

The audience is mainly the elderly, who are used to conventional ways of accessing information. It may be difficult for them to accept TikTok as a short 
video app. The main characteristic of traditional media is that the content disseminated has apparent depth, and the practitioners are generally people with rich experience in the field. Hence, the professional standard and credibility of information are higher.

\subsubsection{Mobile Online Long-form Video: Akiyip and Tencent Video}

The content of long videos is more complete and richer in emotion. TikTok focuses on "fun" content, which is mainly watched in fragments during leisure time.

\subsubsection{Social Networking Platforms: Weibo}

The contents provided by Weibo and TikTok are both young and fragmented. Weibo is more focused on creating hotspots and spreading news and breaking news, while TikTok focuses more on creation.

\subsubsection{Bargaining Power of Buyers}

The main buyers of TikTok are users, advertisers and film companies. Users can purchase value-added services, such as built-in paid features, premium animated stickers and filters. Advertisers mainly promote their ads in TikTok to gain exposure. Film and TV companies post film and TV clips on TikTok for promotion. Since TikTok is not the only platform for advertising, TikTok does not have an advantage in the scarcity of video content. Therefore, TikTok is in a weak position in terms of bargaining power.

\subsubsection{Analysis of TikTok's Market Competition Strategy}

From the analysis of the Five Forces Model theory, it can be seen that in 2016, the short video industry received a large influx of capital and the short video market had strong momentum of development. TikTok faced more significant pressure than the start-up stage. The central pressures were mainly the competitive rivalry, the threat of new entrants, and the threat of substitutes. Therefore, with the increasing variety of short videos and the deepening of video content, TikTok will lead the short videos platforms with accurate positioning, attracting traffic with quality content, continuously improving the forum's differentiation, and strengthening cooperation with other high traffic platforms. The next part of this article will analyze how TikTok seized opportunities at various stages through the Business Model Canvas tool, ultimately taking the industry's lead.

\subsection{Analysis of TikTok Business Model at Each Stage}

\subsubsection{The Business Model of the Initial Stage of TikTok}

As shown in "Table 1", TikTok finally positioned its value as "focusing on the new generation as a 15second music video community" by exploring the development of the product. A more precise customer segmentation was conducted, with users placed at the post-90s generation in first- tier and second-tier cities. TikTok has identified channel access, such as sponsoring popular variety shows like "China's Hip Hop" and "Happy Camp", to increase TikTok's exposure through the celebrity effect. TikTok team believes that the product is always their foundation and they will focuses on the continuous improvement of core resources: algorithms and artificial intelligence technology. In the pre-launch phase of the development, the rhythm of updating a version in an average of 10 days is maintained to bring users a better experience. The primary ways to realize cash are advertising and third-party e-commerce cooperation. 
Table 1. The business model of the initial stage of TikTok

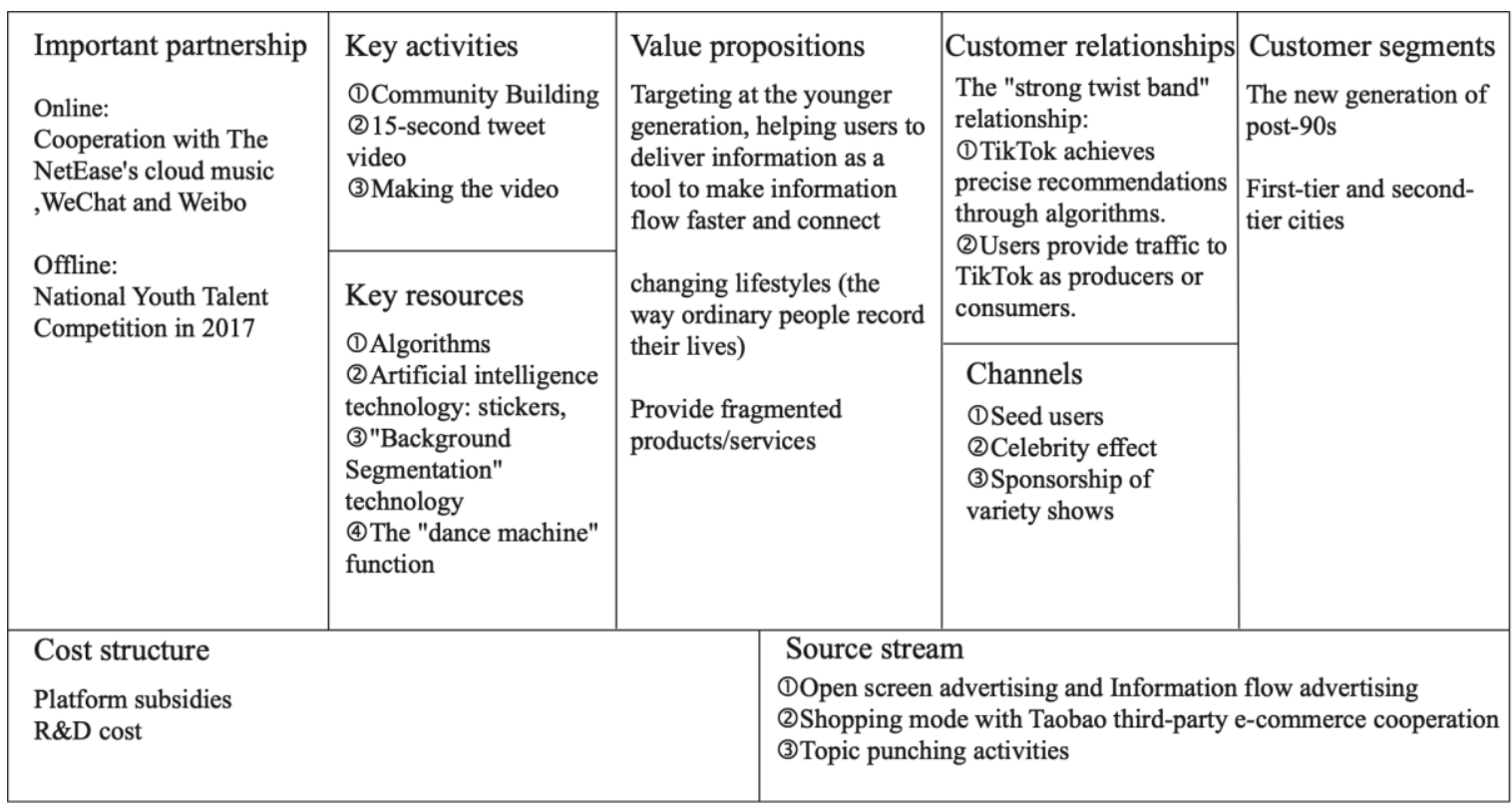

\subsubsection{Problems with TikTok's Business Model at the Initial Stage}

Inadequate platform operation and supervision: there is a risk of unhealthy videos spreading, affecting the mental health of young people

Original videos are easily intercepted and lifted: it is easy to weaken original video makers' motivation, which is not conducive to the long-term development of TikTok.

Lack of original content: The official approach is KOLs (Key Opinion Leaders), who create videos to attract users to imitate them. This way limits creativity and generates aesthetic fatigue.

Single way of realization and lack of profitability: The realisation method through the "fan economy" alone is definite and involves certain risks.

\subsection{The Business Model of the Mature Stage of TikTok}

The analysis on TikTok's maturity phase in "Table 2" shows that TikTok has improved as follows from its start-up phase to its maturity phase.

\subsubsection{Customer Segmentation}

Targeted users gradually sank from first and second-tier cities to third and fourth-tier cities, and the age of the main force rose from 18 - 24 to 24 - 30 years old[6].

\subsubsection{Key Activities}

(1) Launched a minor protection system: In April 2018, TikTok officially launched its anti-addiction system, setting time alerts and time locks. "The Sunflower Project" was launched in July 2018 to optimize the viewing restrictions. In March 2019, TikTok upgraded its Teen Program, selecting video content including education, knowledge and painting for teenagers. In May 2020, TikTok upgraded the Sunflower Project to include a youth guardian function.

(2) Opened up access to videos of 1 to 15 minutes, giving video creators a more expansive space to create better quality videos. 
Table 2. The business model of the mature stage of TikTok

\begin{tabular}{|c|c|c|c|c|}
\hline $\begin{array}{l}\text { Important partnership } \\
\text { (1) Popular influencer } \\
\text { (2) Corporate advertisers to } \\
\text { promote brand publicity } \\
\text { (3) Government: central } \\
\text { enterprises are stationed to }\end{array}$ & $\begin{array}{l}\text { Key activities } \\
\text { (1) Purchase of music rights } \\
\text { Material library (filters, } \\
\text { stickers) } \\
\text { (2) Live streaming function } \\
\text { (sales with goods) }\end{array}$ & \multirow[t]{2}{*}{$\begin{array}{l}\text { Value propositions } \\
\text { "Recording a better life." } \\
\begin{array}{l}\text { Mutual communication } \\
\text { behind the content }\end{array} \\
\begin{array}{l}\text { Emphasizing the user's } \\
\text { personalized experience }\end{array}\end{array}$} & $\begin{array}{l}\text { Customer relationships } \\
\text { Partnerships: mutually } \\
\text { beneficial } \\
\text { (1) Users: consumers, } \\
\text { creators, publishers } \\
\text { (2) TikTok: providing a } \\
\text { platform for two-way } \\
\text { benefits. }\end{array}$ & $\begin{array}{l}\text { Customer segments } \\
\text { It was gradually sinking } \\
\text { from Tier one and two } \\
\text { cities to Tier three and } \\
\text { four cities. }\end{array}$ \\
\hline $\begin{array}{l}\text { (3) Government: central } \\
\text { enterprises are stationed to } \\
\text { promote government work } \\
\text { report }\end{array}$ & $\begin{array}{l}\text { Key resources } \\
\text { Users: Huge number } \\
\text { and extremely active } \\
\text { Algorithm: Vibrant } \\
\text { platform content (19 } \\
\text { categories) }\end{array}$ & & $\begin{array}{l}\text { Channel's } \\
\text { APP } \\
\text { Star effect }\end{array}$ & \\
\hline \multicolumn{2}{|c|}{$\begin{array}{l}\text { Cost structure } \\
\text { (1)Music copyright } \\
\text { (2) Network acceleration cost (CDN) } \\
\text { (3) R\&D cost } \\
\text { (4) Signed celebrities }\end{array}$} & \multicolumn{3}{|c|}{$\begin{array}{l}\text { Source stream } \\
\text { (1)Advertising } \\
\text { (2) Live reward } \\
\text { (3)-commerce: can directly jump to Taobao }\end{array}$} \\
\hline
\end{tabular}

\subsubsection{Key Resources: Development of Technology}

It is predicted that the network penetration rate will be very high in the future, so TikTok team strengthens the accuracy of big data and algorithm functions to enhance the stickiness of users, deeply understands users' needs and preferences, solidifies their habits and penetrates the product into their lives.

\subsubsection{Source Stream}

TikTok increased the diversity of ways to cash in. It Combined advertising with quality short videos, live cash, and cooperated with e-commerce, with a shopping cart button appearing at the bottom of the short video, which can jump directly to Taobao for purchase

\subsection{SWOT Analysis}

\subsubsection{Strategic Choices}

By combining the various opportunities and threats to the TikTok development, a strategic analysis matrix of TikTok's swot is derived ("Table 3").

The analysis shows that the short-form video market still has a good development trend, and the number of daily users is still increasing; Although the state has strengthened its regulation of short-form video, it is still generally supportive of short video development; The development of the Internet economy has led major investors to enter the shortform video industry, which contains enormous development potential. In this context, TikTok has the option of reversing its existing disadvantages and seeking to diversify. Therefore, a diversification strategy and a turnaround strategy are more suitable for TikTok.

\subsubsection{Analysis on Strategic Measures}

According to the SWOT analysis matrix in "Fig. $5 "$, TikTok's future growth strategy is as follows.

\subsubsection{Enhancing $R \& D$ Capabilities and Refining User Positioning}

The competition in the short-video industry is fierce. Enhancing user stickiness is a significant goal for the future. Therefore, TikTok should focus on enhancing its R\&D capabilities, refining users precisely, pushing more accurate content through algorithms, and further expanding new customer groups founded on retaining existing ones.

\subsubsection{Optimizing Video Content and Strictly Controlling the Quality of Goods it Sells}

Quality is an essential cornerstone of the longterm development of an enterprise. Content that is not vulgar and the quality of goods that meet the standard is a crucial criterion for users to judge a platform. On the one hand, TikTok should strengthen the video content auditing. On the other hand, TikTok should optimize video content. While bringing entertainment 
to users, it should also evoke their positive attitudes. Live streaming with goods can help TikTok attract traffic and increase cash flow, however, if the progress is not good, it may cause the loss of users. If
TikTok wants to grow its live-streaming business, it should be strict about the quality so that users think the goods are "worth buying".

Table 3. SWOT Matrix of TikTok

\begin{tabular}{|c|c|c|}
\hline & Strengths & Weaknesses \\
\hline External Factors & $\begin{array}{l}\text { 1.Extremely convenient } \\
\text { 2."Community" character } \\
\text { 3.Advanced algorithms, artificial intelligence } \\
\text { and other technologies: precise targeting of user } \\
\text { preferences } \\
\text { 4.Emphasis on meeting user needs } \\
\text { 5.Large user base and high market share }\end{array}$ & $\begin{array}{l}\text { 1.Entertainment is more skewed: not deep } \\
\text { enough, harder to attract highly educated, high } \\
\text { consumption crowd } \\
\text { 2.Lack of protection for "video patents } \\
\text { 3.Lack of guarantee for the quality of the } \\
\text { "product" } \\
\text { 4.Insufficient video audit }\end{array}$ \\
\hline Opportunities & Growth strategy（SO） & Torsion strategy (WO) \\
\hline $\begin{array}{l}\text { 1.The inevitability of the times( } 5 \mathrm{G} \text { era to } \\
\text { improve the performance of mobile devices),big } \\
\text { data and artificial intelligence technology } \\
\text { maturity(analysis of users and capture the user's } \\
\text { preferences are becoming more and more } \\
\text { successful) } \\
\text { 2.The inclination of image-based content } \\
\text { 3.Fragmentation of relaxation time }\end{array}$ & $\begin{array}{l}\text { Strengthen R\&D capabilities and } \\
\text { enhance user stickiness } \\
\text { Explore efficient realisation models and } \\
\text { grow steadily }\end{array}$ & $\begin{array}{l}\text { Strictly control the quality of products } \\
\text { Establish a mechanism to protect originality }\end{array}$ \\
\hline Threats & Diversification strategy(ST) & Defense strategy(WT) \\
\hline $\begin{array}{l}\text { 1.Extremely convenient } \\
\text { 2."community" character } \\
\text { 3.Advanced algorithms, artificial intelligence } \\
\text { and other technologies: precise targeting of user } \\
\text { preferences } \\
\text { 4.Emphasis on meeting user needs } \\
\text { 5.Large user base and high market share }\end{array}$ & $\begin{array}{l}\text { Optimise video content and increase the } \\
\text { audit system } \\
\text { Strengthen the ability to innovate and } \\
\text { enhance market development }\end{array}$ & $\begin{array}{l}\text { Strictly control the quality of goods } \\
\text { Optimise video content, increase vetting } \\
\text { system }\end{array}$ \\
\hline
\end{tabular}

\subsubsection{Expanding the User Base}

Smart phones' wave is also surging among the elderly groups, TikTok can take this opportunity to attract the elderly, for example, by producing videos on health and disease prevention.

\subsubsection{Optimizing Product Details}

On the one hand, TikTok should optimize the beauty filters to attract female users. On the other hand, the video interface has been optimized with a video progress bar to avoid wasting users' time watching repetitive parts.

\section{CONCLUSION}

Analyzing the internal and external environment faced by TikTok before the start-up stage through Porter's five forces model, the short video was a period of rapid expansion of the industry value in 2016. TikTok seized the opportunity by analyzing the environment and competitors, initially positioning the product, targeting the target users, capturing part of the market through a cold start. Afterwards, it should open up the market and win attention with celebrity effects and sponsorship of popular variety shows.

Development of a start-up contains different stages, including start-up and mature stages. The Business Model Canvas tool can clarify the characteristics and problems of TikTok at distinct stages. TikTok's business model is not yet complete in the start-up phase, with a single channel, immature vital business, and a single way to make money. During the mature phase, TikTok has optimized all aspects of its business model. It has continued to segment its target audience, introduced a system to protect minors in line with its policies, enhanced the accuracy of its algorithm features, gained a deeper understanding of its users' needs and preferences, made continuous optimizations to its video features and increased the variety of ways to realize cash.

The SWOT tool analysis shows that TikTok should adopt a turnaround and diversification strategy to reverse its existing disadvantages and explore more steadily while maintaining its existing users. 


\section{AUTHORS' CONTRIBUTIONS}

This paper is independently completed by Yuan Peng.

\section{ACKNOWLEDGMENTS}

First and foremost, I would like to show my deepest gratitude to professor Matthew Grimes, who have provided me with valuable guidance. Further, I would like to thank all my friends for their encouragement and support. Without all their enlightening instruction and impressive kindness, I could not have completed my thesis.

\section{REFERENCES}

[1] Central People's Government of the People's Republic of China. The 47th statistical report on the development of the Internet in China $[\mathrm{R}] .2021$

[2] Amit, R., \& Zott, C.. (2001). Value creation in e-business. Strategic Management Journal, 22(6-7), 493-520.

[3] The Business Model: An Integrative Framework for Strategy Execution. Richardson J. Strategic Change. 2008

[4] Business Model Generation. Osterwalder A. Privately published. 2009

[5] Zhang Snap \& Li Jia. (2012). A study of the differences in key influencing factors and mechanisms of action between first-time entrepreneurs and re-entrepreneurs: matching opportunities, resources and capabilities. Research and Development Management (06), 116-125. doi:10.13581/j.cnki.rdm.2012.06.013.

[6] iResearch. (2016). China short video industry development research report 2016. Shanghai iResearch Market Consulting Co. (eds.) iResearch Consulting Series Research Report (2016, No. 9) (pp. 133-182). 